\title{
BLENDING OF POLYSTYRENE AND LOW DENSITY POLYTHENE TO ENHANCE THE PHYSICAL PROPERTIES BY USING COMPATIBILIZER-STYRENE ETHYLENE/BUTYLENE STYRENE
}

\author{
Dr. B. RAJAM
}

Associate Professor, University College of Technology, Osmania University, Hyderabad,India

\begin{abstract}
Polymers are materials made of long, repeating chains of molecules. These polymers are blended to improve the properties. Blending is the process of combination of two or more polymers which produce a new polymer with improved properties. In this study blending is used to enhance the physical properties of Polystyrene/low density polythene(PS/LDPE) by using compatibilizer like styrene ethylene/butylene styrene. With this blending, the variation of thermal, mechanical and morphological properties of PS and LDPE with SEBS as compatibilizer is studied. Blends with different compositions of PS/LDPE in 100/0, 80/20, 60/40, 40/60, 20/80 and 0/100 wt\% were prepared through melt blending in a twin screw extruder at a temperature of $200^{\circ} \mathrm{C}$ and a screw speed of $60 \mathrm{rpm}$. The compatibilizer (SEBS) with $5 \%$ concentration of total weight of the blends was used. Various tests were conducted for the mechanical properties. Morphological behaviors was observed.It showed different variations in properties like tensile, flexural decreased and compressive properties increased with increase in LDPE content used in the blend. However the elongation at break of the blends tended to increase with increasing LDPE. Impact strength of the blends increase slowly with LDPE up to 40 wt\%, after that it increases sharply with increasing LDPE. The impact energy of the LDPE -rich blends exceeded with that of pure LDPE. The optimum properties like elongation at break and impact strength of PS and LDPE blends are observed at 60 wt\% of LDPE content in polystyrene and low density polyethylene blend.

KEYWORDS: Polymers, Polystyrene, Low density polythene, Blending, Compatibilizer\& Extrusion
\end{abstract}

Received: May 31, 2020; Accepted: Jun 20, 2020; Published: Jun 30, 2020; Paper Id.: IJMPERDJUN2020277

\section{INTRODUCTION}

Blending is an efficient way to produce new polymers with improved properties. This study is focused on the blending of polystyrene (PS) and low density polyethylene (LDPE). It also improve some deficient properties of polymers. Despite the high performance, the cost of block and graft copolymers, the PS/LDPE blend system is considered immiscible and incompatible due to benzene rings in the PS and straight carbon chains of aliphatic kind in the LDPE. So compatibilizer is used for miscibility purpose. One of the compatibilizer is styreneethylene/butylene-styrene, which is effective due to PS and EB blocks of SEBS are miscible with PS and LDPE blends respectively. By adding this SEBS observed improvements in properties through an affinity and polarity concept. In this study the effects of this compatibilizer on mechanical and thermal properties of PS/LDPE are reported.Compatibilizers are used to promote interfacial adhesion between pair of polymers which are otherwise immiscible. 


\subsection{Extrusion}

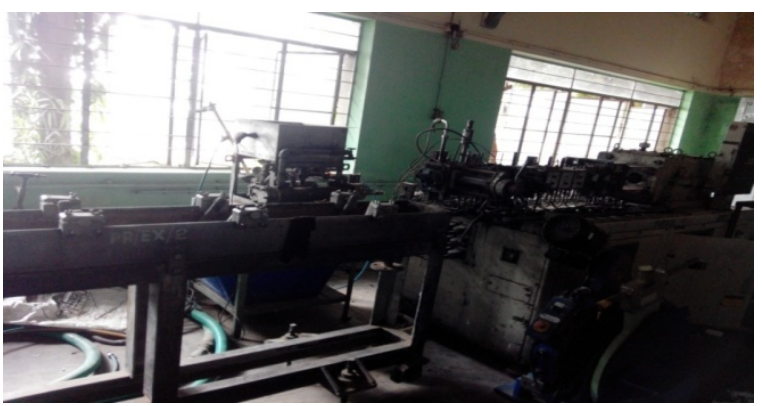

Figure 1.1: Twin Screw Extruder

\subsection{Injection Moulding}

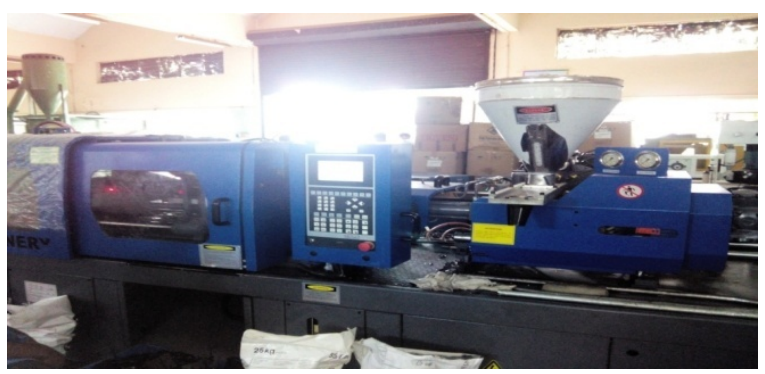

Figure 1.2:Injection Moulding

1.3 Universal Testing Machine

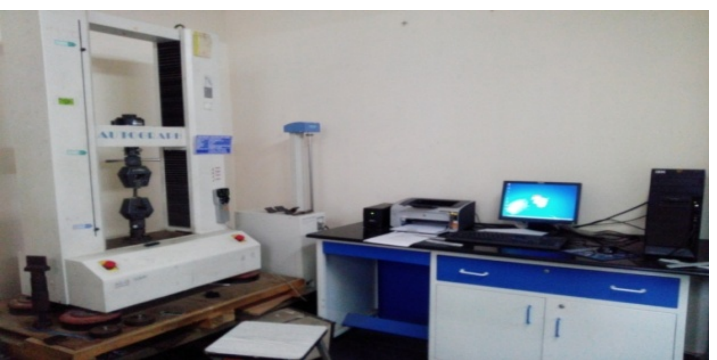

Figure 1.3: Universal Testing Machine

\subsection{Tensile Strength}

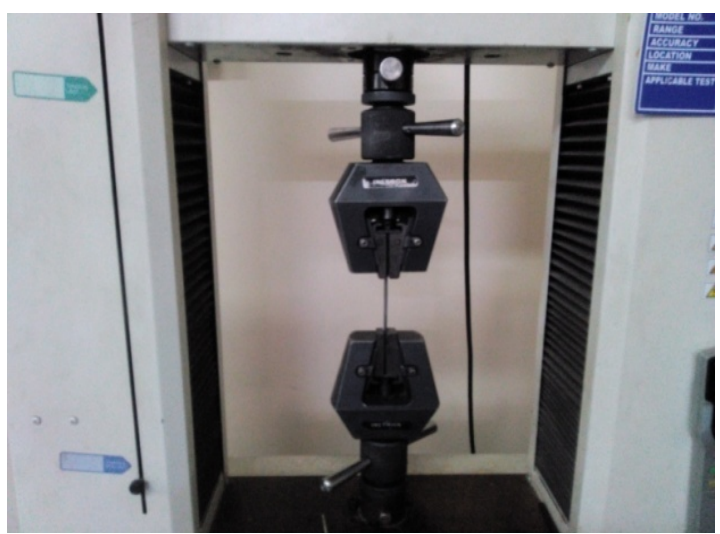

Figure 1.4: Tensile Strength 

by using Compatibilizer-Styrene Ethylene/Butylene Styrene

\subsection{Flexural Strength}

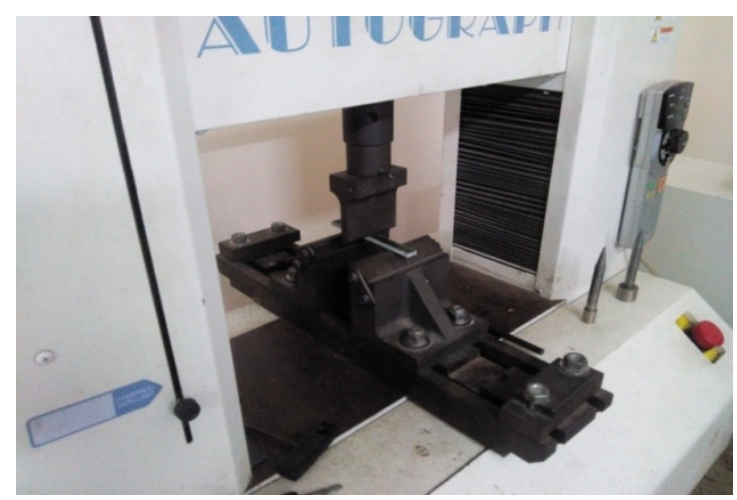

Figure 1.5 Flexural Strength

1.6 Compressive Strength

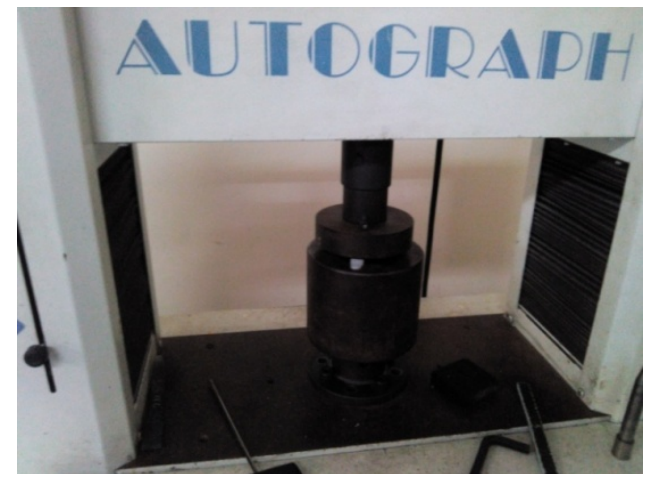

Figure 1.6 Compressive Strength

\subsection{Impact Strength}

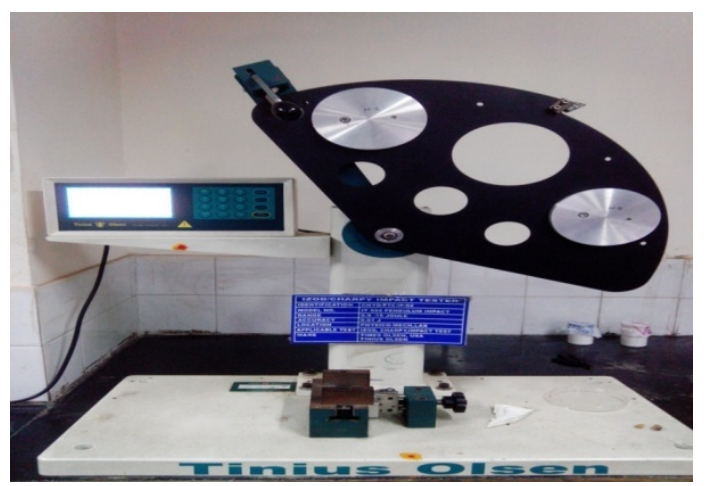

Figure 1.7:Impact Strength

1.9 Heat Deflection Temperature 


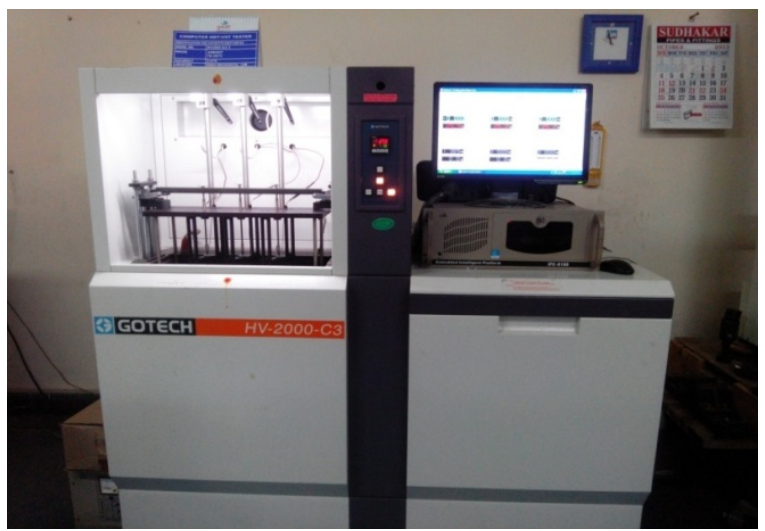

Figure 1.8 Heat Deflection Temperature

\subsection{0: Melt Flow Index}

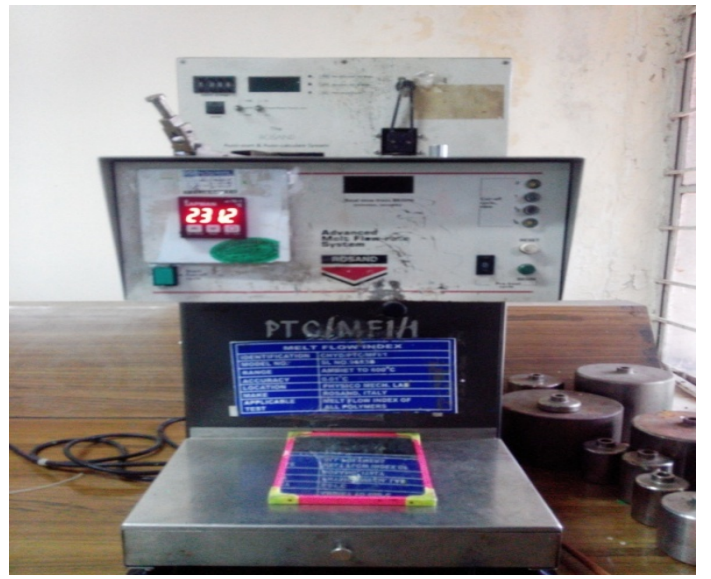

Figure 1.9:Melt Flow Index

\subsection{Scanning Electron Microscope}

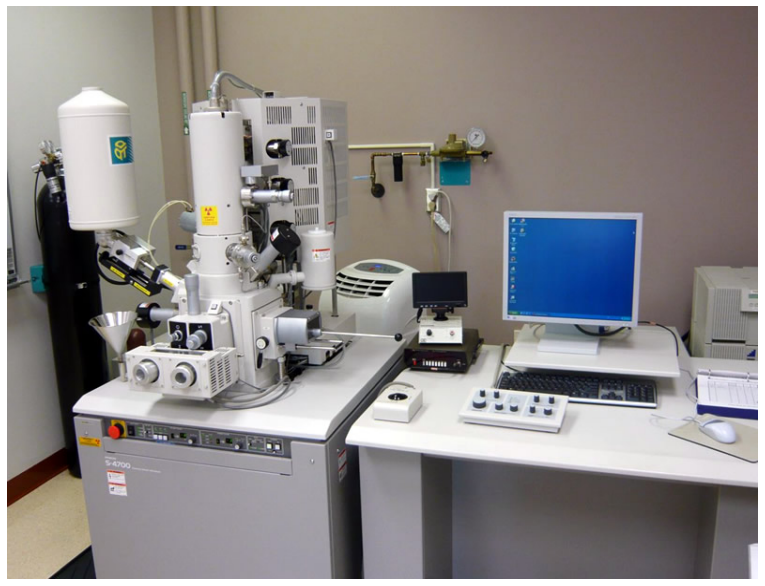

Figure 1.10:Scanning Electron Microscope

\section{MATERIALS AND METHODS}

\subsection{Materials Used}

Polystyrene, Low density polyethylene and styrene ethylene / butylene styrene (SEBS). 
Table 2.1: The Materials and Specifications

\begin{tabular}{|l|l|l|}
\hline \multicolumn{1}{|c|}{ Material } & \multicolumn{1}{c|}{ Grade } & \multicolumn{1}{c|}{ Supplied by } \\
\hline Polystyrene(PS) & HPPS HH-30 & H.P Polymers, Fathenagar, Hyderabad \\
\hline Low density polyethylene(LDPE) & $16 \mathrm{MA400}$ & H.P Polymers, Fathenagar, Hyderabad \\
\hline Styrene-ethylene/butylene-styrene(SEBS) & $99.5 \%$ CAS & $\begin{array}{l}\text { Kinetic polymers, } \\
\text { Jeedimetla, Hyderabad }\end{array}$ \\
\hline
\end{tabular}

\subsection{Experimental Procedure}

\section{Preparation of Blends}

Polystyrene (PS) and Low density polyethylene (LDPE) blends were prepared with different compositions of 100/0, $80 / 20,60 / 40,40 / 60,20 / 80$ and 0/100 by weight of $3 \mathrm{kgs}$ and mixed. 150 grams of SEBS is added to every batch as compatibilizer. Then it is extruded in a twin screw extruder at $200^{\circ} \mathrm{C}$ and $60 \mathrm{rpm}$ speed to get a uniform mixture. The product obtained is like a thin thread, is cut into pieces of $2 \mathrm{~cm}$ length and sent to injection molding. The polymer is melted and injected into the mold which can be fixed according to the desired shape and size for testing. Then the polymer is cooled to make it solidify and is taken out for testing different physical, chemical and thermal properties. The specimen is tested mechanical properties like tensile, flexural, compressive and impact strength by using Universal Testing Machine. Thermal properties are tested by Heat Deflection Temperature, Melt flow index apparatus.

\section{RESULTS AND DISCUSSIONS}

\subsection{Tensile Strength}

According to ASTM-D -790, tensile test was done at the cross head speed $5 \mathrm{~mm} / \mathrm{min}$ with compatibilizer and without compatibilizer.

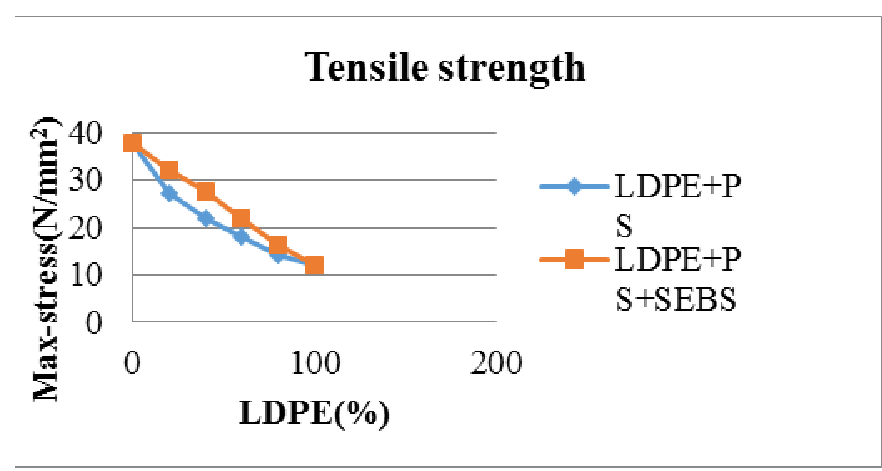

\section{Figure 3.1: Effect of LDPE on Tensile Strength of PS/LDPE Blends with and without compatibilizer}

From Figure 3.1 observed that increase in wt\% of LDPE decreases the tensile strength with compatibilizer slightly higher than without compatibilizer. This is due to pure PS exhibits a brittle fracture at low elongation.

\subsection{Elongation at Break}




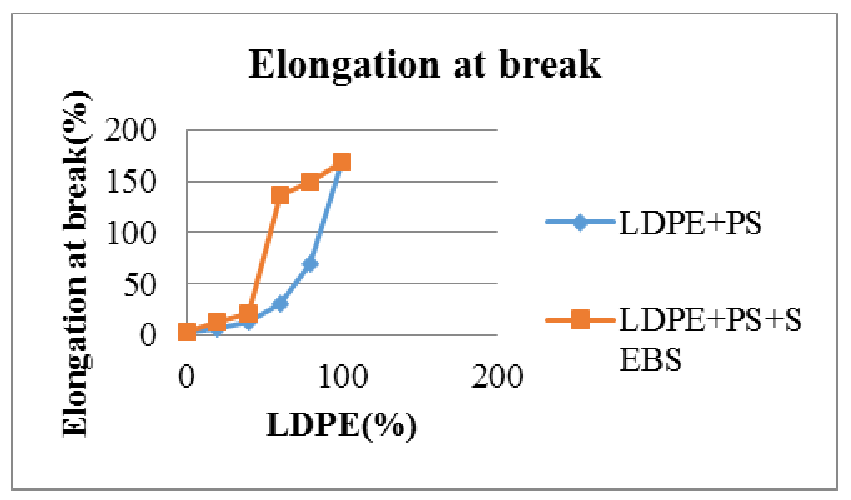

Figure 3.2: Effect of LDPE on Elongation at Break with and without Compatibilizer

From Figure 3.2 observed that the elongation at break increase gradually with increasing LDPE upto $40 \mathrm{wt} \%$, and then a sharp increase. It is noted that addition of $5 \mathrm{wt} \%$ SEBS resulted in overall improvement. So, SEBS is effective compatibilizer.

\subsection{Flexible Strength}

According to ASTM-D-790, flexural test was done at 100mm support span and $3 \mathrm{~mm} / \mathrm{min}$ rate of cross head speed with and without compatibilizer

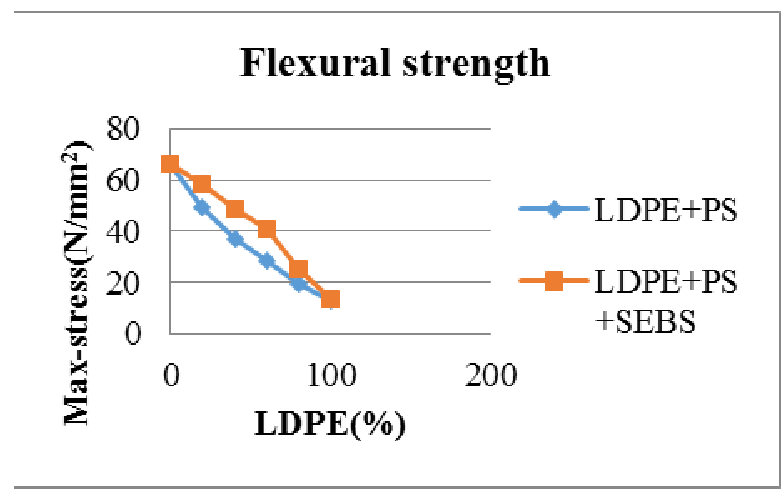

Figure 3.3: Effect of LDPE on Flexural Strength of PS/LDPE with and without Compatibilizer

From Figure 3.3 observed that flexural strength decreases with increase in LDPE. The flexural strength is higher for compatibilizer when comparing without compatibilizer.

\subsection{Compressive Strength}

\section{Compressive strength}

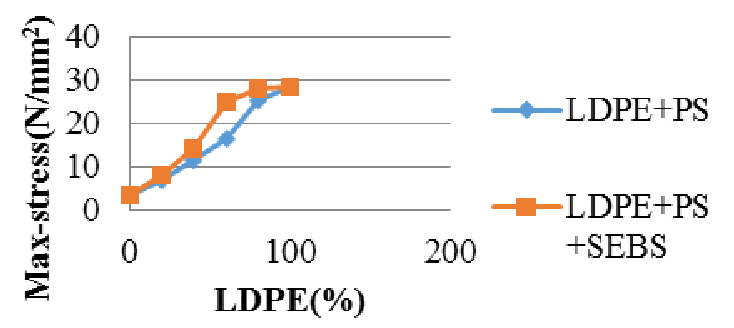

Figure 3.4: Effect of LDPE on Compressive Strength with and without Compatibilizer 

by using Compatibilizer-Styrene Ethylene/Butylene Styrene

From Figure 3.4 observed that compressive strength increases with increase in LDPE. The compressive strength is higher for with compatibilizer.

\subsection{Impact Strength}

According to ASTM-D-256, impact strength was done. The specimen is clamped vertically as a cantilever beam so that the notched end of the specimen is facing the striking edge of the pendulum

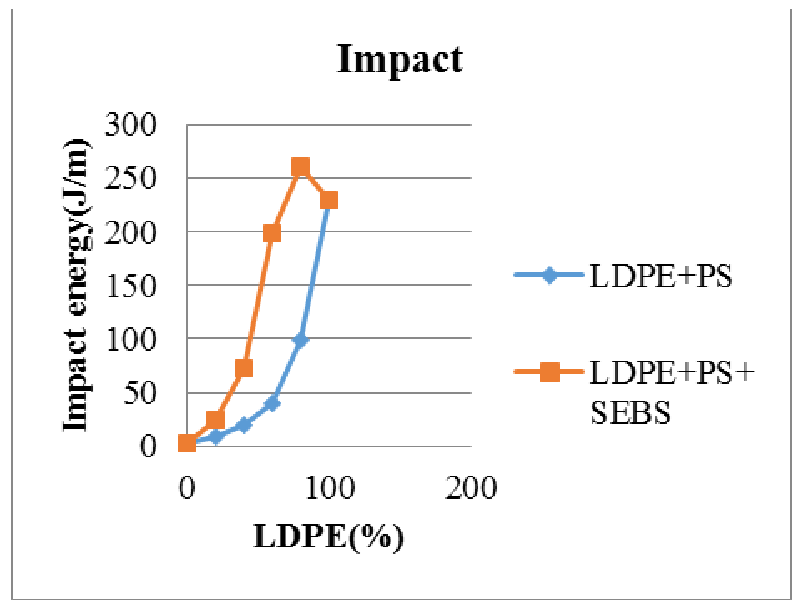

Figure 3.5: Effect of LDPE on Impact Strength of PS/LDPE with and without compatibilizer

From Figure 3.5 observed that impact strength is increased slowly with $40 \mathrm{wt} \%$ of LDPE content, and then sharply increased. It is noted that $80 \mathrm{wt} \%$ of LDPE content is having more impact strength when comparing without compatibilizer.

\subsection{Heat Detection Temperature}

It is the most important factor for finding the efficiency of engineering plastics. It is the temperature at which a polymer deforms. This property can be applied in product design, engineering, and manufacturing of products using thermoplastic components. This test was conducted according to ASTM-D-648. The test specimen is loaded in three point bending in edgewise direction at $18.5 \mathrm{~kg} / \mathrm{cm}^{2}$ outer fiber stress and temperature is increased by $2^{\circ} \mathrm{C} / \mathrm{min}$ until the specimen deflects $0.254 \mathrm{~mm}$.

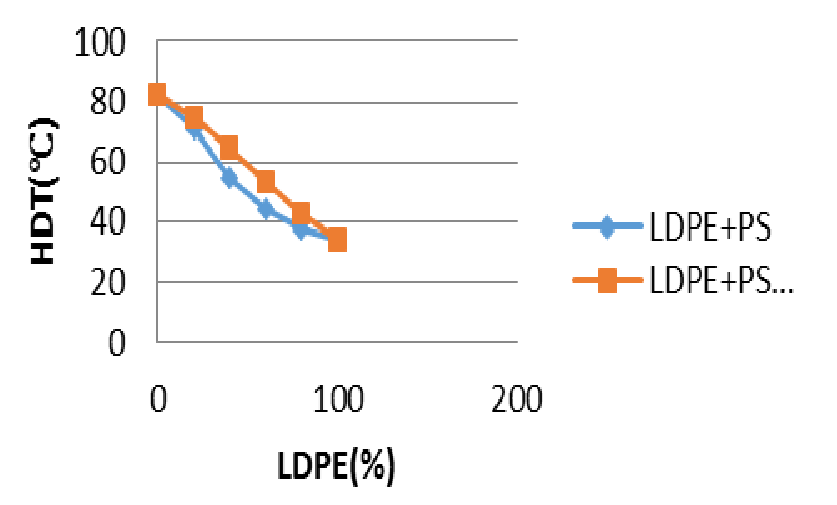

Figure 3.6: Effect of LDPE on HDT with and without Compatibilizer

From Figure 3.6 observed that the HDT decreases with increasing LDPE. 


\subsection{Melt Flow Index}

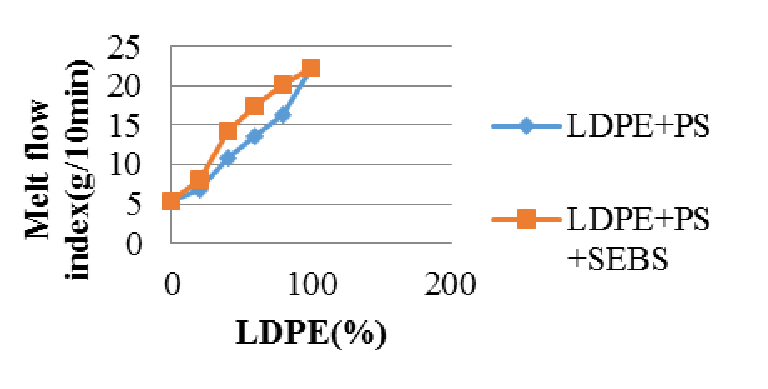

Figure 3.7: Effect of LDPE on Melt Flow Index with and without Compatibilizer

From Figure 3.7 it is observed that MFI is increased with increasing LDPE content.

3.8 Scanning Electron Microscope(SEM)

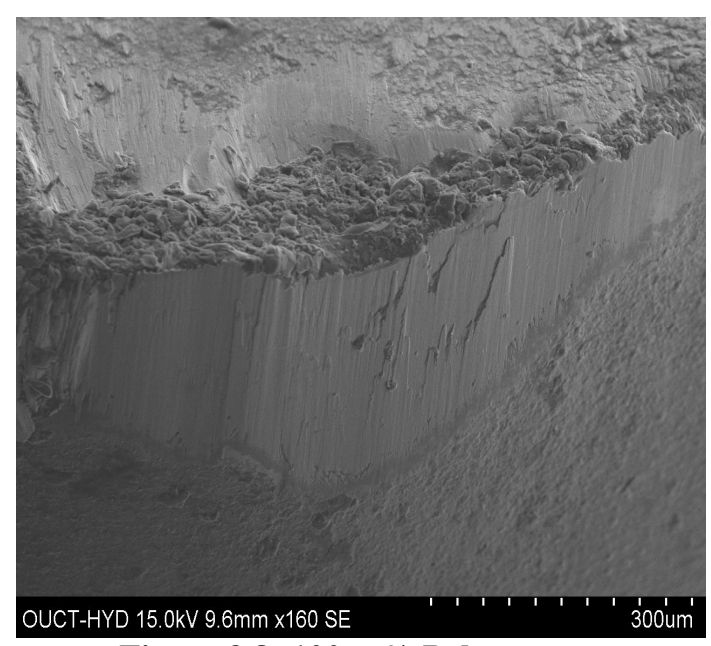

Figure 3.8: 100wt\% Polystyrene

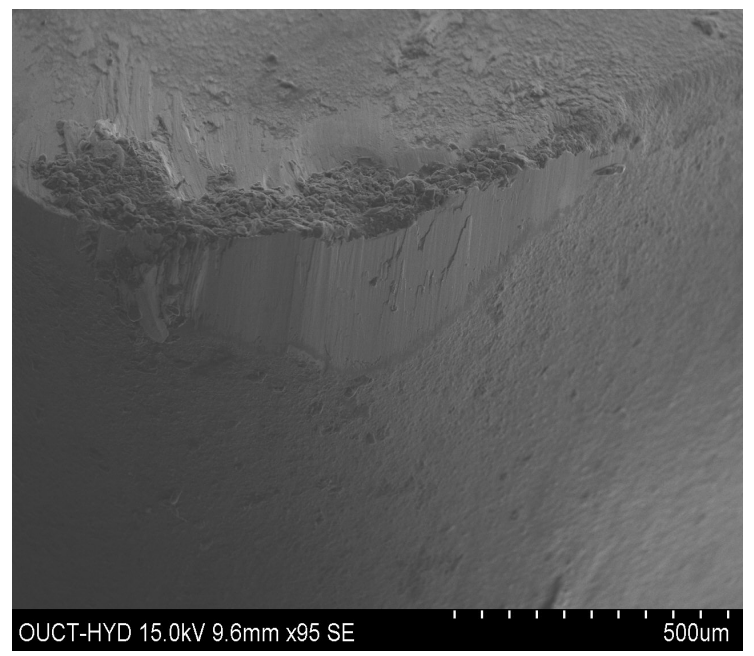

Figure 3.9: 100wt\% LDPE 

by using Compatibilizer-Styrene Ethylene/Butylene Styrene

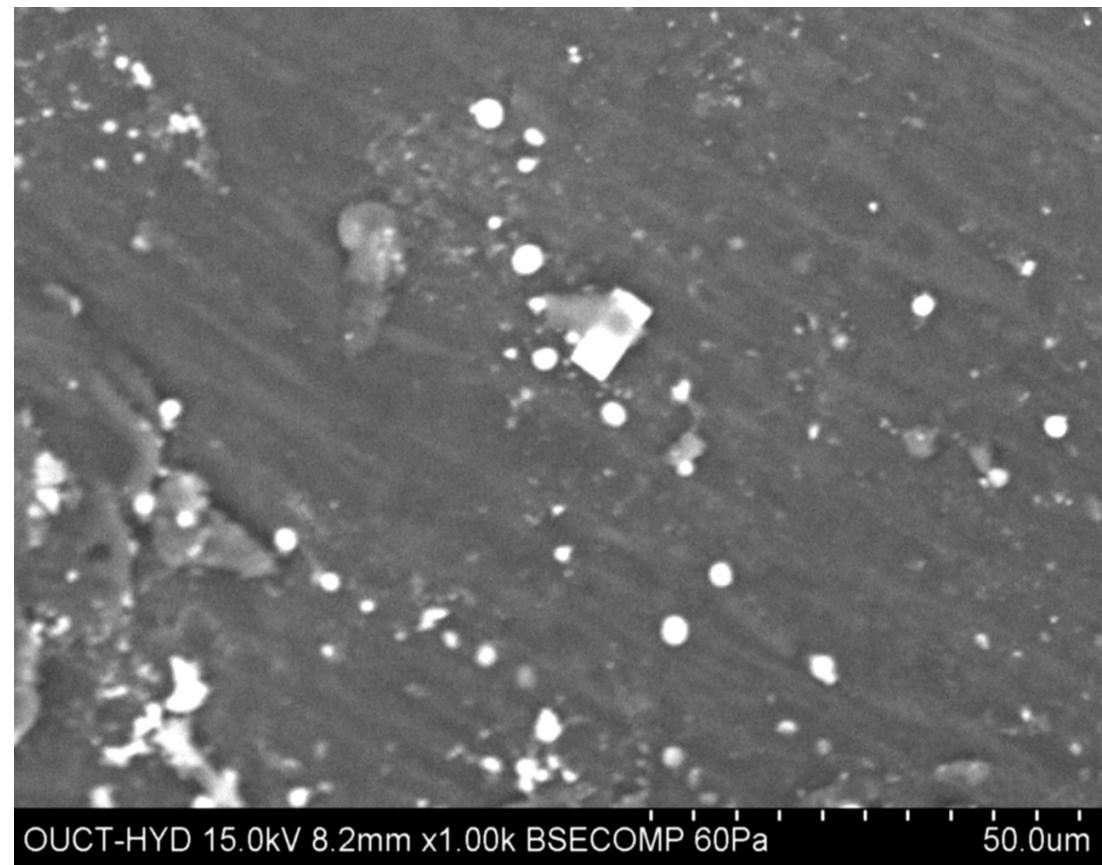

Figure 3.10: 40/60 wt\% PS/LDPE without SEBS

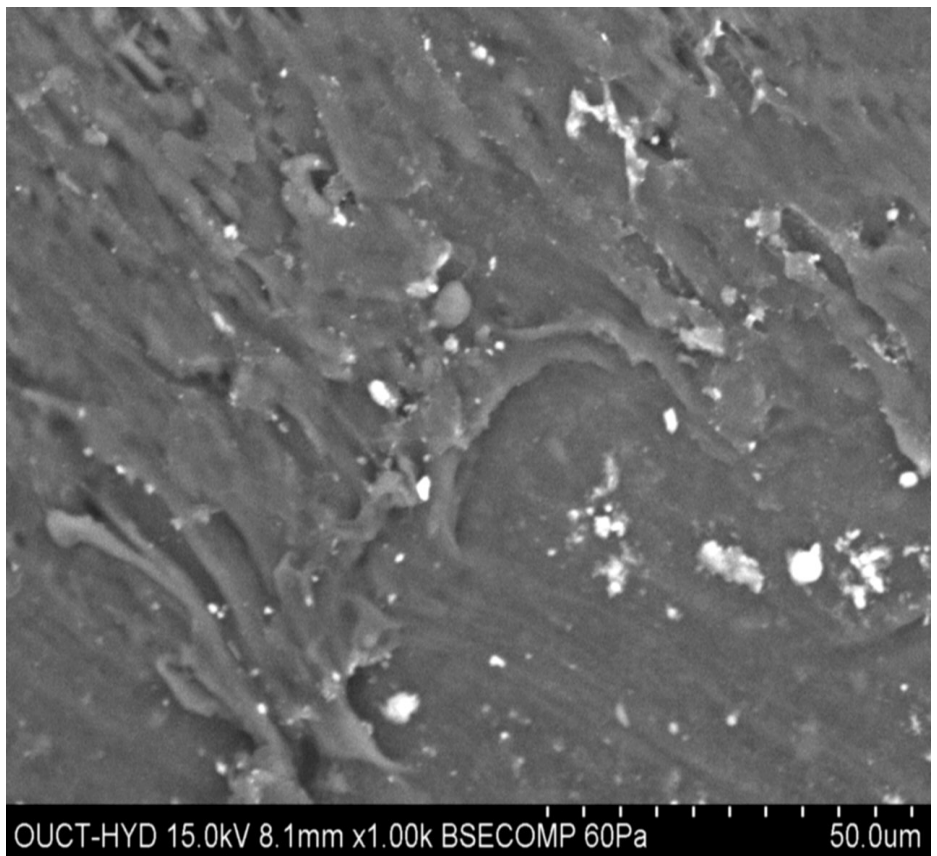

Figure 3.11: 20/80 wt\% PS/LDPE without SEBS 


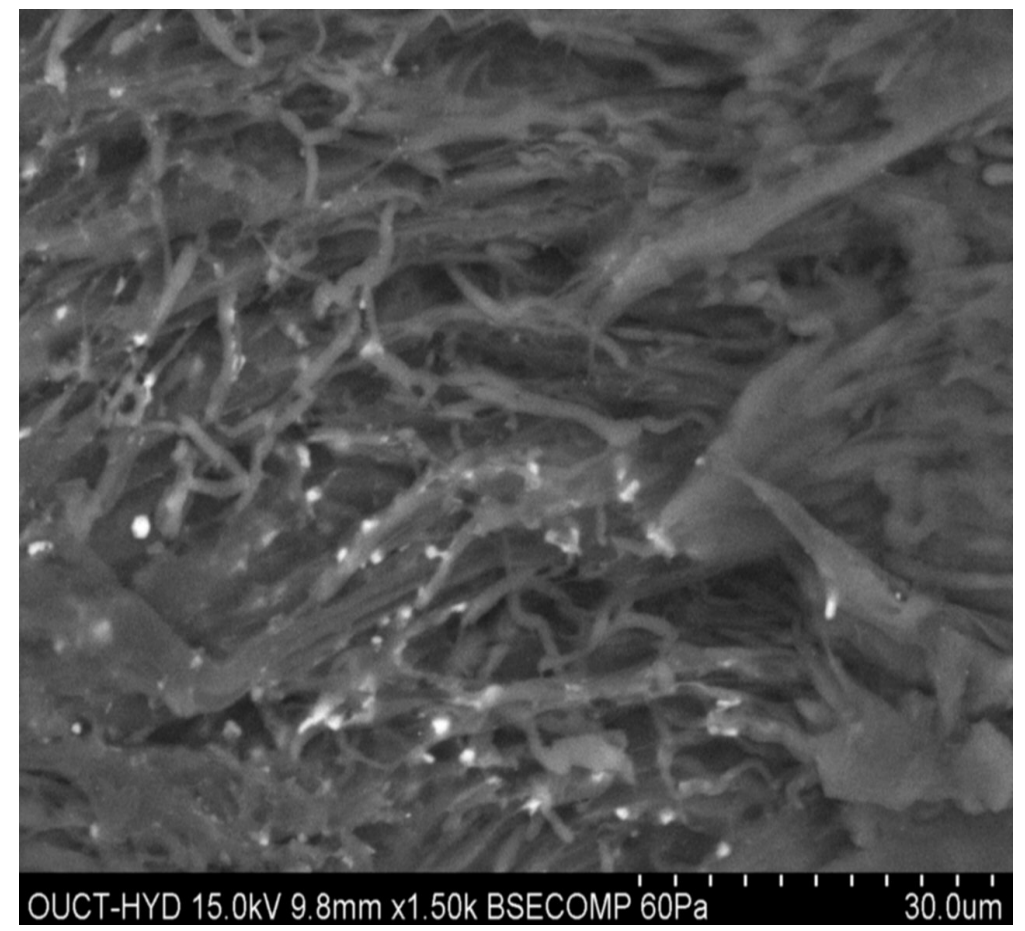

Figure 3.12: 40/60 wt\% PS/LDPE with SEBS

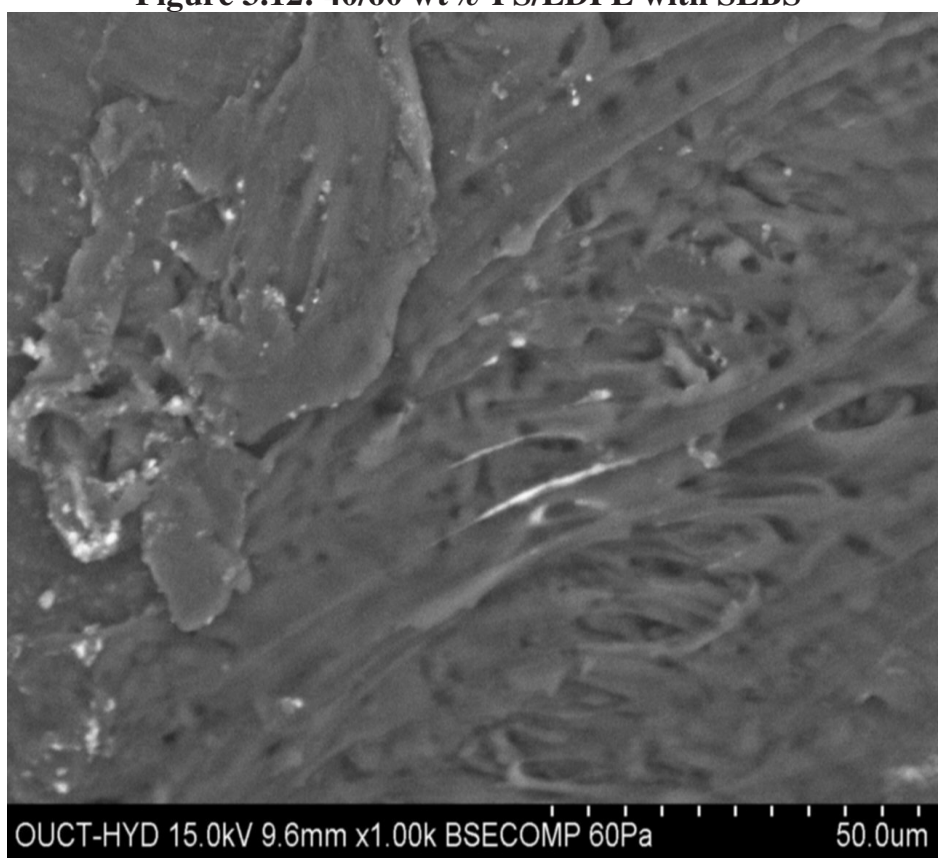

Figure 3.13: 20/80 wt\% PS/LDPE with SEBS

The Scanning Electron Microscope photos of PS/LDPE blends and PS/LDPE/SEBS blends are shown in Figure 3.8 to 3.13. These demonstrate a typical matrix droplet structure, which indicates immiscibility between PS and LDPE as shown in Figure 3.10 and 3.11. It can be observed that matrix droplets in PS/LDPE blends decreases at SEBS, and size distribution also becomes more uniform in the Figure 3.12 and Figure 3.13.

It is observed from Figure 3.12 and Figure 3.14, the average diameter of the dispersed PS phase becomes smaller as the weight fraction of LDPE increases in the PS/LDPE/SEBS blends. Which indicates that SEBS increases the interfacial adhesion between the PS and LDPE blends and miscibility increases as LDPE increases.The optimum miscibility of PS and LDPE blends with SEBS is obtained at 40/60 wt\% of PS/LDPE blends. 


\section{CONCLUSIONS}

In this study a cheaper and flexible, toughened and better commercial grade polymer are produced. It stated that improved properties are observed when compared to individual polymers without compatibilizer which results in reducing production cost for materials which require the use of expensive material. Tensile and flexural properties decreased with increase in LDPE composition due to increase in interfacial adhesion of the polymer blends. The elongation at break of the blends increases with increasing LDPE up to $40 \mathrm{wt} \%$ and then increases sharply with increase in LDPE. Compressive properties increased with increase in LDPE in the blends of PS and LDPE. Impact strength of the blends increases slowly with LDPE up to $40 \%$ and then it increases with increasing LDPE. The impact energy of the LDPE-rich blends exceeded that of pure LDPE at $80 \mathrm{wt} \%$ of the LDPE content. Heat deflection Temperature. Heat deflection Temperature decreases with increase in weight percentage of LDPE. Melt flow index value increases with increase in LDPE weight percentage. Morphological observation showed that the blends with SEBS as compatibilizer are miscible, increase the interfacial adhesion and decreases the phase dispersion between the components. The optimum miscibility was obtained at $40 / 60 \mathrm{wt} \%$ of PS/LDTE blends.

\section{REFERENCES}

1. H.F.Guo, S.Packirisamy, R.S.mani, C.L.Aronson, D.J.Meier (1999) "Effect of compatibilizers on polystyrene (PS) and low density polyethylene (LDPE) blends" journal of applied polymer science.

2. GenjieJiang, Hong Wu and ShaoyunGuo(2012) "A Study on Compatibility and Properties of POE/PS/SEBS Ternary Blends" journal ofMoleculer science part B physics.

3. Shi-Ai Xuand Chi-Ming Chan(2005) "Polystyrene/Low Density Polyethylene Blends Compatibilized by a Tri-Block Copolymer I. Properties and Morphology" journal of applied polymer science.

4. G.TenBrinke and E. Kroeze (2004) "Compatibilization of low-density polyethylene/polystyrene blends by segmented EB(PSblock-EB)n block copolymers" journal of Polymer Bulletin.

5. ShialXu, Ming Jiang and JingshuShen (1994) "Morphology and deformation mechanism of polystyrene and low density polyethylene blends studied by TEM" journal of polymer journal.

6. Shi-Ai Xu, Jing-Wei Xie and Ming Jiang (1999) "Morphology and deformation of compatibilizedpolystyrene low density polyethylene blends" journal of Polymer International.

7. MaohamedTaha and Valerie frerejean (2001) "mechanical and morphology development of LDPE/PS blend compatibilization" journal of applied polymer science.

8. Jianming Li, Pei Lian Ma and Basil D.Favis (2002) "The Role of the Blend Interface Type on Morphology in Cocontinuous Polymer Blends".

9. G. J. Nam,K. Y. Kim and J. W. Lee(2004) "The Effect of SEBS on Interfacial Tension and Rheological Properties of LDPE/PS Blend" journal of applied polymer science

10. Nam G. J., KimK. Y. and Lee J. W.( 2005) "The effect of SEBS on interfacial tension and rheological properties of LDPE/PS blend" journal of applied polymer science

11. Sousa, A.R., Amorim, K.L.E., Medeiros, E.S., Melo, T.J.A and Rabello, M.S., (2005). "The combined effect of photo degradation and stress cracking in polystyrene”. Polymer degradation and stability.

12. VesnaRek and Nina Vranjes (2007) "Morphology and Properties of SEBS block Copolymer Compatibilized PS/LDPE Blends" 
journal of Elastomers and plastics Polymer International.

13. Weihua Tang, Jian Tang, Huilin Yuan and Riguang Jin(2007) "The compatibilization effect of ethylene/styrene interpolymer on polystyrene/polyethylene blends" journal of polymer science.

14. P.NoorunnisaKhanam and MariamAl Ali AIMaadeed(2014) "Processing and characterization of polyethylene-based composites" journal ofAdvanced Manufacturing: Polymer \& Composites Science

15. KarolyDobrovszky and FerencRonkay(2015) "Investigation of compatibilization effects of SEBS-g-MA on polystyrene/polyethyleneblend with a novel separation method in melted state” journal of Polymer Bulletin.

16. M. Tasdemir and I. Miskioglu,(2015) "The Effect of Styrene-Ethylene-Butadiene-Styrene on the Friction and Wear Properties of Polystyrene/Low Density Polyethylene Blends", Advanced Materials Research.

17. Grassie, N and G. Scott (1985) polymer degradation and stabilization, chapter 4, Cambridge university press, Cambridge.

18. Imamovic, Z., Saric, I., Hajradinovic, D., \&Hadziabdic, V. Analytical and Numerical Analysis Of Injection Molding Tools Of Asa Polymers.

19. Vasudha, D., Devi, M. R., Suhasini, M., Anusha, N., Niranjan, P., \&Boddeda, B. Polymers and Plasticizers Used In Transdermal Drug Delivery: An Overview.

20. Bhambri, P. A. L. L. A. V. I., \& Fleck, B. R. I. A. N. (2016). Drag Reduction using high molecular weight polymers in TaylorCouette Flow. Int. J. Mech. Prod. Eng. Res. Dev, 6, 59-72. 